\title{
A new view of water dynamics on germinating diaspores: physiological perspectives from biophysical measurements
}

\author{
João Paulo Ribeiro-Oliveira ${ }^{1}$, Marli Ranal ${ }^{2}$, and Marco Boselli ${ }^{2}$ \\ ${ }^{1}$ Universidade Federal de Uberlandia - Campus Umuarama \\ ${ }^{2}$ Federal University of Uberlandia
}

May 5, 2020

\begin{abstract}
We demonstrated that classical biophysical measurements of water dynamics on germinating diaspores can improve the understanding of the germination process in a simpler, safer and newer way. This was done using diaspores of cultivated species as a biological model. To calculate the water dynamics measurements (weighted mass, initial diffusion coefficient, velocity and acceleration) we used the mass of diaspores recorded over germination time. Weighted mass of germinating diaspores has a similar pattern, independent of the physiological quality, species or genetic improvement degree. However, initial diffusion coefficient (related to imbibition per se), velocity and acceleration (related to the whole germination metabolism) are influenced by species characters, highlighting the degree of genetic improvement and physiological quality. Changes in the inflection of velocity curves demonstrated each phase of germination sensu stricto. There is no pattern related to the number of these phases, which could range between three and six. Regression models can demonstrate initial velocity and velocity increments for each phase, giving an idea of management of germinative metabolism. Our finds demonstrated that germination is a polyphasic process with a species-specific pattern, but still set by the degree of genetic improvement and (or) physiological quality of diaspores. Among the biophysical measurements, velocity has the greatest potential to define the germination metabolism
\end{abstract}

\section{Hosted file}

Ribeiro-0liveira, Ranal and Boselli.docx available at https://authorea.com/users/303177/ articles/434854-a-new-view-of-water-dynamics-on-germinating-diaspores-physiologicalperspectives-from-biophysical-measurements

\section{Hosted file}

fig1_art_pca(1).jpg available at https://authorea.com/users/303177/articles/434854-anew-view-of-water-dynamics-on-germinating-diaspores-physiological-perspectives-from-

biophysical-measurements 

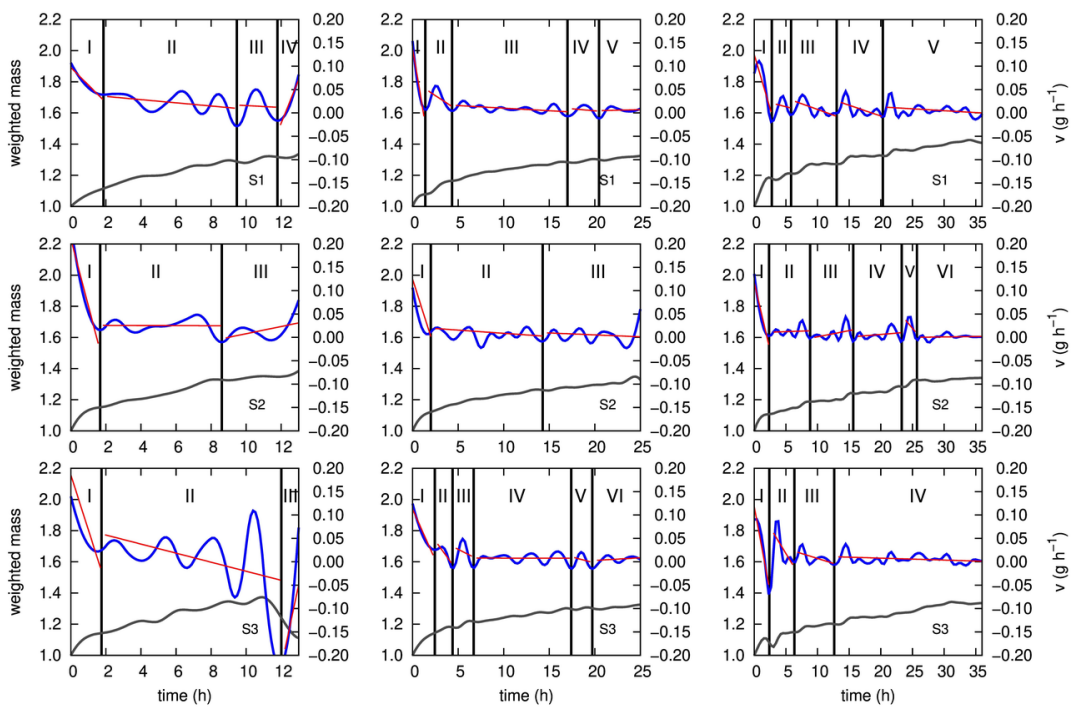